\title{
Young adults' accounts of buying rounds of alcoholic drinks for friends: Implications for harm reduction
}

\author{
Sima Riazi ${ }^{1,2}$ and Sarah MacLean ${ }^{3,4}$ \\ ${ }^{1}$ Melbourne Medical School, University of Melbourne, Victoria, Australia \\ ${ }^{2}$ Austin Health, Heidelberg, Victoria, Australia \\ ${ }^{3}$ Melbourne School of Population and Global Health, University of Melbourne, Victoria, Australia \\ ${ }^{4}$ Centre for Alcohol Policy Research and Department of Community and Clinical Allied Health, La Trobe University, Bundoora, Victoria, \\ Australia
}

\begin{abstract}
Aims: Buying or shouting rounds (purchasing alcoholic drinks for oneself and others at the same time) at on-premise licensed venues, such as nightclubs and bars, is a widespread Australian cultural practice. Our paper aims to provide detailed information on young adults' attitudes and practices concerning round buying.

Methods: Thematic analysis of research interviews involving 60 young adults living in Melbourne was conducted using NVivo 10 , yielding three key themes.

Findings: (1) Contexts where round buying occurred: young adults considered group size and culture, as well as bar activity, when determining whether they should round buy with their friends. In busy venues, round buying conveniently reduced the number of trips to and time waiting at the bar. Round buying was less likely to occur in groups larger than 4-5 people, as beyond this participants found it difficult to control the reciprocity of round buying, cost, and consumption of alcohol. (2) Sociability: while round buying did not occur within the friendship groups of all participants, it was seen by many as an important way of demonstrating connections with friends. (3) Consumption: overwhelmingly, participants believed that round buying increases their overall alcohol intake through implicit and explicit pressures to consume more.

Conclusions: Policies that limit round buying may offer a means to reduce alcohol-related harm. In addition, education that challenges round buying rules and expectations may help alleviate pressure on young adults to consume heavily.
\end{abstract}

\section{Introduction}

Young adults are more likely than any other age group to report drinking at risky levels and consuming quantities that place them at risk of alcohol related injury and harm (Australian Institute of Health and Welfare [AIHW], 2011; MacLean \& Callinan, 2013; McCreanor et al., 2013; Measham, 2006; Measham \& Brain, 2005). While numerous studies have identified factors that drive heavy drinking across the 18-24 year old age group, little is known about the impact of round buying, which has a long history in public drinking places (Mass Observation, 1943). Young adults commonly frequent on-premise licensed venues such as clubs and bars. Buying or shouting rounds (purchasing alcoholic drinks for themselves and others at the same time) at these venues has been described as a widely established Australian cultural practice (De Crespigny, Vincent, \& Ask, 1999; VicHealth, 2013).
A small number of published studies focus specifically on round buying, but many of these are decades old (AIHW, 2011; e.g., Aitken, 1985; Barbara, Barnes, \& Usher, 1978; Knibbe, Van De Goor, \& Drop, 1993). The practice, however, is also referred to in qualitative studies of drinking (e.g., Herring, Bayley, \& Hurcombe, 2014; Measham \& Brain, 2005). Research on round buying identifies a number of themes, including the impact of round buying on relationships, social rules and expectations that govern round buying, and how overall consumption is affected (Aitken, 1985; Barbara et al., 1978; Knibbe et al., 1993).

Round buying appears to play a significant role in the friendships of individuals; however, depending on the age and gender of an individual, round buying has different meanings. An Australian qualitative study by Barbara et al. (1978) examined round buying among Sydney men, finding it to be an "expression of mateship", a means to "symbolise...equality... (and) reciprocity." The authors

Correspondence: Dr. Sima Riazi, Austin Health, 145 Studley Rd, Heidelberg VIC 3084. Email: sima.riazi@austin.org.au

Financial support: This research was supported in part by the Australian Research Council (LP 100100017) and VicHealth.

Declaration of interest: The authors have no conflicts of interest to declare.

Keywords: alcohol, young adults, round buying, treating, intoxication, Australia 
state that round buying creates a sense of exclusivity, by defining the group's boundaries. A study of drinking behaviours among United Kingdom teenagers found that round buying provided a means to demonstrate independence and, when accepting shouts from the opposite sex, sexual equality (Dorn, 1980).

Round buying appears to be bound by social rules. For example, it is rude to decline an invitation to participate in round buying; it is unacceptable to leave a drinking group without shouting a round and/or before everyone else has shouted a round; and it is improper to get too far behind in drinking (Barbara et al., 1978). However, the rules governing round buying appear to vary. In Glasgow, Aitken (1985) found that the majority of male latecomers to a group benefited from round buying but did not purchase reciprocal drinks.

Existing research suggests that when people buy rounds, the amount of alcohol consumed over a single setting increases (Aitken, 1985; Barbara et al., 1978; Knibbe et al., 1993). The reason for this is twofold. Firstly, round buying increases the duration of a drinking session, and secondly it increases the rate of alcohol consumption. Barbara et al. (1978) shows that a new set of rounds frequently commences without the knowledge of all the drinkers in a group. This prohibits drinkers from leaving a group before everyone has purchased their round in the new set. As it is unacceptable to fall behind in a round, individuals modify their drinking rates to conform to that of the group, which is determined by the fastest drinker (Barbara et al., 1978). Another study in the Netherlands found that buyers purchased the next round of drinks as soon as the first member of the group had finished his or her drink (Knibbe et al., 1993), creating pressure on slower drinkers to consume alcohol more rapidly. Aitken (1985) suggests that heavier drinkers usually purchase rounds of alcohol, whereas light drinkers more often only purchase drinks for themselves. One strategy employed by light drinkers to circumvent heavy alcohol consumption is to avoid participating in round buying (Herring et al., 2014).

Young Australians' alcohol consumption at bars and nightclubs is associated with harms to health and with assault (AIHW, 2011; Livingston, 2013). Despite this, no studies considering specific attitudes and practices associated with round buying in contemporary contexts are available to inform policy and harm reduction strategies. The purpose of this study is to provide this information.

\section{Methods}

\section{Participants}

To understand how young people view and participate in round buying, 60 Melburnians aged between 18-24 years (mean age of 20.8 years; $S D=2.1$ ) who reported consuming at least one alcoholic drink within the previous six months were interviewed. They were accessed via local tertiary institutions, agencies, and through word of mouth. Participants were offered the choice of completing interviews on their own $(n=35)$, or with one $(n=16)$ or two $(n=9)$ other young people whom they already knew. This enabled us to access individual accounts of round buying and also to understand something of how round buying occurs among friends.

\section{Procedure}

The purpose of interviews was to elicit detailed accounts of the role of alcohol within participants' lives. Three experienced researchers conducted the interviews. The interview component reported on here involved asking participants what they think about the custom of shouting drinks for others and the circumstances in which they think it is good idea to pay for rounds of drinks. As a conversational style was used to explore concerns raised by interviewees in relation to drinking, interviews covered slightly different material (Bourdieu, 1996).

Of the 60 participants interviewed, 51 (mean age of 20.7 years; $S D=2.1$ ) discussed the practice of round buying and are reported on here. There was an almost equal gender split of 25 men and 26 women. Eleven of these participants drank within the recommended National Health and Medical Research Council (NHMRC) guidelines of four or fewer standard drinks within a single session (NHMRC, 2009). Thirty-nine of the 51 young adults who discussed round buying mentioned that they participate in it themselves (including 20 women and 19 men).

At the conclusion of each interview, a brief survey of demographic characteristics and a screening tool to identify drinking patterns were administered. Participants were provided with a gift voucher to reimburse them for their time and travel expenses. Ethics approval was obtained from the two universities involved in the study.

\section{Analysis}

Thematic analysis of the qualitative interviews was conducted using NVivo 10 (QSR International Pty Ltd., 2012). After discussion, the authors identified three themes within the interview data: (1) the context where round buying occurred, (2) the function of round buying in enhancing sociability, and (3) the effects of round buying on overall alcohol consumption. SR initially coded all transcripts. SM then coded a random sample comprising over $20 \%$ of all transcripts to ensure agreement on attribution of data to identified themes. Of 24 Kappa scores calculated for the double coded transcripts, only three showed a score of less than 0.75 , with scores of 0.98 or over for 15 source/node combinations, indicating a high degree of agreement between the coders. Pseudonyms were used to disguise the identity of participants and quotations selected as typifying comments of participants.

\section{Results}

\section{The Contexts in which Round Buying Occurs}

Three factors play an important role in determining whether or not young adults in the study sample participated in 
round buying: group size, wait times at the bar, and group culture.

Group size. Participants in our study identified that drinking group size influenced whether or not round buying occurred in their friendship groups. An upper limit of four to five individuals was frequently mentioned as the threshold beyond which round buying was unsuitable. Common reasons included that larger group sizes made it more difficult for young adults to control the reciprocity of round buying, overall spend, overall alcohol consumption, and to keep track of who the recipients of a purchased round were. A lack of reciprocity can cause conflict between drinkers, as summarised by Bella (21, female), "some people might not shout a round for everyone and then it's unequal and it will cause tension". In reference to round buying in larger groups, Edith (19, female), complained that she ended up buying drinks for people she didn't even like, saying "A lot of money is wasted on getting too drunk...and then you wake up and you're like 'Oh why did I spend that dollars on that horrible person?'”. Edith's quote clearly identifies how round buying in larger groups can increase the overall spend on alcoholic drinks and reduce the control young adults have over their drinking and who they purchase alcohol for.

Group culture. The decision to shout rounds by young adults was also determined by whether or not it was part of the culture of the group to do so. This may be influenced by the ethnic composition of the group. For example, Parvani (24, female) and Naresh (23, male) both noted that when drinking with Asian friends, each bought their own drinks. They viewed round buying as an Australian practice, as Naresh explained, "I’ve got Aussie friends here as well...if I'm with... my Aussie friends... then obviously we shout out the rounds so you, you know I'll, I'll go for one round of beer then probably somebody else [will buy a round].”

Time at the bar. The feasibility of approaching the bar and prolonged serving times also influenced whether or not participants bought alcoholic drinks in rounds. During busy periods, participants found round buying convenient. Sending one person to the bar to purchase drinks for the group reduced the number of trips made and time spent at the bar waiting. Moreover, the cost of a round and a trip to the bar could be shared by a number of group members. Some young adults only favoured round buying at the start of the night, where each member of a drinking group was responsible for purchasing one round before they began purchasing their own drinks. Common reasons included difficulties remembering who was next to shout a round after three to four drinks had been consumed, and pressures to consume more alcohol than desired if round buying continued.

\section{Round Buying and Sociability}

While round buying did not occur within the friendship groups of all study participants, it was regarded by many as an important way of demonstrating a connection with friends. For example, round buying allowed participants to care for one another on a night out by paying for a greater share of rounds for friends (MacLean, 2016). In this manner, friends who couldn't afford alcoholic drinks could still attend outings and drinking activities. Almost all participants agreed that it was reasonable for friends with more disposable income to shout a greater share of rounds. This was a particularly common view among participants who were employed. Ethan (18 male, employed full-time) stated, "If my mates have got no money and I've got a lot, like I'll help them out. Why not, it’s just a beer?”.

In some friendship groups, reciprocal rounds were purchased across a number of evenings, allowing friends without income on a particular night to drink and participate in the group's activities. Some participants included paying for food and transport home as part of the division of costs for the night; therefore, those who had avoided shouting a round could pay for other items.

Avoiding your round was often viewed by participants as sneaky and unfair. However, young adults acknowledged that including people that you don't know well in a round or having a very large group meant that reciprocal drinks may not be purchased, and the cost of drinks wouldn't be equally shared. Purchasing a round for a disparate group of people was therefore sometimes an act of largesse or generosity.

Participants in our sample found that certain alcoholic drink types were more appropriate for round buying than others, the most popular of which were jugs of beer and shots. Depending on the drink purchased, round buying had different meanings. While jugs of beer were purchased for the sake of convenience, shots were consumed in groups to celebrate achievements and special events in young peoples' lives, which helped to cement friendships. Parvani (24, female) stated, "shots is something you don't really do alone cause it's always the entire group doing it”.

Round buying generally involved purchasing a number of drinks of the same beverage for a group of friends. This could make it difficult for young people to connect socially if they didn't like the type of drink purchased. However, two interviewees noted that it was still possible to participate in round buying, even if a different drink was preferred, by giving extra money to the person responsible for shouting the round.

\section{Effect of Round Buying on Overall Consumption}

Of the 51 participants who discussed round buying, 20 also expressed their views on the impact of round buying on their overall alcohol intake. All but one of these 20 participants believed that round buying increased their alcohol consumption. This view was held across both genders and did not differ between participants who drank within or in excess of levels recommended by the NHMRC guidelines.

Young adults consume more alcohol when drinks are purchased in rounds for a number of reasons, including the expected reciprocity of round buying, as described by Honey (24, female) who stated, "There have been times when... I've not necessarily wanted to drink anymore, but 
it's been my round and I've had to go and buy a jug. And so I think it can encourage getting drunk ...definitely."

The decision to round buy is not always discussed and can commence without agreement from others in a group. Polly's (23, female) account clearly illustrates how people end up drinking more when round buying is the assumed practice:

For example, on Tuesday night I met a girl from school for a drink and she said 'Oh I'll shout the first ones'...I...sort of thought I'd have one drink to save on money and everything. But then, if she shouts the first drink, then you have to shout the second two. So I guess you end up drinking more that way than if you were just buying yourself a drink.

Some participants experienced implicit pressures to keep up with the drinking rate of others (Barbara et al., 1978; Knibbe et al., 1993). The effect of this, as Mitchell (23, male) explained, is to encourage drinkers to conform to the pace of the fastest drinker in the group:

I always keep an eye on...the height of everybody else's drink. Like... if we're out and it's in a glass, obviously I'll notice that I'm drinking slowly and I'll speed up the process, because I think, well, you know, we are doing rounds here...Last night...I was hanging out with my mate, I noticed that...he was drinking a beer. He was drinking it quite fast and so I would, you know, while talking just sort of indiscreetly, like, just pick it up and just sort of like drink a fair bit of it. You know like, take a few swallows quite quickly and then notice where it was evened out and we would just continue....

If drinkers in a group are not keeping up with their friends, pressures to drink more may come in the form of another drink, as Aidan (18, male) describes, "you could be half way through a beer and they could hand you another one....”.

Similarly, Sol (21, male) spoke of how his friends pressure him to finish his drink so that another jug of beer can be purchased for the group “....Like 'come on man, let's finish this like why, why aren't you finishing this?... it's time to have another jug, come on finish your drink.' Yeah, yeah they do that all the time".

\section{Discussion}

Both men and women buy rounds at licensed venues in Melbourne. Little to no difference could be found across gender regarding views about round buying, round buying practices, or the impact of round buying on overall consumption.

This study shows that round buying serves a number of functions for both young men and women. For example, it conveniently reduces trips to and time spent at the bar and it allows young adults to demonstrate connections with friends. Rounds of shots, in particular, are used to celebrate special events in young peoples' lives (Measham \& Brain, 2005).

Overwhelmingly, participants in our study believed that round buying encouraged them to drink more, through both implicit and explicit pressures. Participants identified social rules, such as expectations of reciprocity, that govern round buying which are associated with drinking more. This is consistent with past international research (Barbara et al., 1978; Knibbe et al., 1993). Education that challenges these rules and expectations may help alleviate pressures on young people to heavily consume. While participants appeared cognisant that round buying increases their overall alcohol intake, few discussed strategies that they were able to employ to withstand pressures to consume more. Identifying and disseminating strategies to enable young adults to resist pressure to buy rounds should be part of any education campaign about limiting alcohol consumption associated with round buying.

Alcohol researchers agree that measures targeting alcohol supply and price are the most effective means of reducing heavy consumption (Babor et al., 2010). Policies that limit the purchase of multiple drinks at one time have a long history and may offer a means to reduce harms associated with round buying (Grundy, 2010; Mass Observation, 1943). Such drink restrictions have been trialed in three Victorian late night venues, but not evaluated (Houston \& Stark, 2008). In one study in Newcastle, restricting numbers of drinks that could be purchased at one time to four was part of a suite of measures, including enforcing earlier closing times for licensed venues. The measures were associated with a significant reduction in night time assaults; however, the direct effect of drink restrictions was inconclusive (Miller et al., 2012). A subsequent study suggested that the reduction in night time assaults was due to earlier closing hours rather than restrictions on multiple drinks sales (Kypri, McElduff, \& Miller, 2014). As studies repeatedly identify that drinkers believe they consume greater quantities of alcohol when they engage in round buying, it would be useful to conduct further research wherever round buying restrictions are implemented to identify whether these bans have an effect on either consumption or harms.

This paper provides current information about how young people view and practice round buying in Melbourne, Australia. Further observational studies of round buying would enable researchers to understand the micro-group processes involved, how people are pressured to drink more, and how people manage not to purchase a round when they want to leave a venue or stop drinking.

\section{Acknowledgements}

We would like to thank Matsumi Karasaki and Christine Siokou for their contribution in interviewing participants. Hume City Council, Yarra City Council and the Municipal Association of Victoria each made in-kind contributions to 
the project. We acknowledge Robin Room from the Centre for Alcohol Policy Research and David Moore from the National Drug Research Institute at Curtin University for guidance of the study on which this paper draws.

\section{References}

Aitken, P. P. (1985). An observational study of young adults' drinking groups - II. Drink purchasing procedures, group pressures and alcohol consumption by companions as predictors of alcohol consumption. Alcohol and Alcoholism, 20(4), 445-457.

Australian Institute of Health and Welfare. (2011). 2010 National Drug Strategy Household Survey Report (Drug Statistics Series No. 25, Cat. No. PHE 145). Canberra, Australia: AIHW

Babor, T., Caetano, R., Casswell, S., Edwards, G., Giesbrecht, N., Graham, K., . . . Rossow, I. (2010). Alcohol: No ordinary commodity: Research and public policy (2nd ed.). Oxford: Oxford University Press.

Barbara, F., Barnes, N., \& Usher, J. (1978). The rules of 'shouting' in drinking groups in Sydney public bars. Australian Journal of Social Issues, 13(2), 119-128.

Bourdieu, P. (1996). Understanding. Theory, Culture \& Society, 13(2), 17-37.

De Crespigny, C., Vincent, N., \& Ask, A. (1999). Young women's social drinking in context - Pub style: A study of decision making and social drinking of young women in urban South Australia. Contemporary Drug Problems, 26(3), 439-456.

Dorn, N. (1980). Alcohol in teenage cultures: A materialist approach to youth cultures, drinking and health education. Health Education Journal, 39(3), 67-73.

Grundy, J. (2010, December 11). 'Lloyd George's beer' or When it was illegal to buy your round [Online article]. Retrieved from http://www.westernfrontassociation. com/component/content/article/160-life-on-the-homefront/1591-lloyd-georges-beer-or-when-it-was-illegalto-buy-your-round.html

Herring, R., Bayley, M., \& Hurcombe, R. (2014). "But no one told me it's okay to not drink": A qualitative study of young people who drink little or no alcohol. Journal of Substance Use, 19(1-2), 95-102.

Houston, C., \& Stark, J. (2008, October 3). It's no one's shout in anti-binge trial. The Sydney Morning Herald. Retrieved from http://smh.com.au

Knibbe, R. A., Van De Goor, I., \& Drop, M. J. (1993). Contextual Influences on young people's drinking rates in public drinking places: An observational study. Addiction Research \& Theory, 1(3), 269-278.

Kypri, K., McElduff, P., \& Miller, P. (2014). Restrictions in pub closing times and lockouts in Newcastle, Australia five years on. Drug \& Alcohol Review, 33(3), 323-326.

Livingston, M. (2013). To reduce alcohol-related harm we need to look beyond pubs and nightclubs. Drug \& Alcohol Review, 32(2), 113-114.

MacLean, S. (2016). Alcohol use and the constitution of friendship for young adults. Sociology. 50(1), 93-108.
MacLean, S., \& Callinan, S. (2013). "Fourteen dollars for one beer!" Pre-drinking is associated with high-risk drinking among Victorian young adults. Australian \& New Zealand Journal of Public Health, 37(6), 579585.

Mass Observation. (1943). The pub and the people: A worktown study. London: V. Gollancz Ltd.

McCreanor, T., Lyons, A., Griffin, C., Goodwin, I., Barnes, H. M., \& Hutton, F. (2013). Youth drinking cultures, social networking and alcohol marketing: Implications for public health. Critical Public Health, 23(1), 110120.

Measham, F. (2006). The new policy mix: Alcohol, harm minimisation, and determined drunkenness in contemporary society. International Journal of Drug Policy, 17(4), 258-268.

Measham, F., \& Brain, K. (2005). 'Binge' drinking, British alcohol policy and the new culture of intoxication. Crime, Media, Culture, 1(3), 262-283.

Miller, P., Tindall, J., Sonderlund, A., Groombridge, D., Lecathelinais, C., Gillham, K., . . . Wiggers, J. (2012). Dealing with alcohol-related harm and the night-time economy: Final report (Monograph Series No. 43). Canberra, Australia: National Drug Law Enforcement Research Fund (NDLERF).

National Health and Medical Research Council (NHMRC). (2009). Australian guidelines to reduce health risks from drinking alcohol. Retrieved from NHMRC website: https://www.nhmrc.gov.au/_files_nhmrc/publications/ attachments/ds10-alcohol.pdf

QSR International Pty Ltd. (2012). NVivo qualitative data analysis software (Version 10) [Computer software].

VicHealth. (2013). Drinking-related lifestyles: Exploring the role of alcohol in Victorians' lives. Melbourne, Australia: Victorian Health Promotion Foundation. Retrieved from VicHealth website: https://www.vichealth.vic.gov.au/media-andresources/publications/drinking-related-lifestyles 